\title{
Packs per Day
}

National Cancer Institute

\section{Source}

National Cancer Institute. Packs per Day. NCI Thesaurus. Code C133746.

The number of cig arettes smoked in a 24 hour period, considered in 20-cigarette units. 